\title{
Field observations and finite element 3-D analysis of soil displacements close to unsupported excavation
}

\author{
Ala Nasir Aljorany ${ }^{1, *}$ and Ghusoon Sadiq Al-Qaisee ${ }^{2}$ \\ ${ }^{1}$ College of Engineering, Baghdad University, Baghdad, Iraq \\ ${ }^{2}$ Institute of Technology, Middle Technical University. Baghdad, Iraq
}

\begin{abstract}
Soil displacements due to unsupported deep excavation may cause severe damages to the nearby structures and foundations systems. Such excavations affect the state of stresses and displacements field of the surrounding soil. In this study, the soil displacements at five observation points were continuously monitored for 23 days, which was the time period of excavation of about $7 \mathrm{~m}$ deep open tunnel. The reference points were installed on the ground surface at horizontal distance ranging from 1.25 to $3.25 \mathrm{~m}$ from tunnel excavation edge. The construction work was related to the project of developing the Army Channel/ Zeyouna section in the Eastern part of Baghdad City. The field observations indicate upward vertical displacement and outward lateral displacements during the first 10 days when the excavation depth was within $4 \mathrm{~m}$. After that, the displacement trend was generally reversed. The displacement values were within $12 \mathrm{~mm}$ and vary from one observation point to another depending on the lateral distance of each point from excavation edge. The finite element package PLAXIS 3D was used to simulate the problem after obtaining the required soil parameters by an extensive site investigation. The analysis results in general, compare well with the field observations in terms of soil displacements at the reference points, especially during the first 10 days. This finding may reveal the reliability of the analysis results at other locations in the surrounding soil.
\end{abstract}

\section{Introduction}

Open excavations for constructing high rise buildings in crowded inhabited areas have become increasingly a common practice in civil engineering. Such excavations are often deeper than the foundations level of the adjacent buildings. Unless there is a well-designed shoring and sound support, these excavations will necessarily cause lateral and vertical movements of the soil mass surrounding the excavated pits, [1-8]. Such movements may cause severe damages to the adjacent structures. The design of these excavations should therefore include an estimation of the ground movement as well as a stability check of the adjacent buildings, [26]. For example, a deep foundation pit nearby a subway line in Taipei was excavated and caused the line tunnel damages and great economic losses, [2]. Fig. 1 displays a case study of a collapsed 13-floor building in Shanghai, China due to an adjacent deep excavation and a heavy rainfall, [2\& 9].

The patterns of movement of a soil mass surrounding an open excavation can be explained as follows:

Removing the excavated soil mass is eventually unloading the soil from its geostatic stress state. The resulting displacements due to this unloading are related to the soil elastic rebound. The surrounding soil will, generally, be displaced upward while the pit's sides tilt outside the excavation center in the horizontal direction.
The other pattern of soil mass movement is related to the loss of lateral support upon excavation. The pit sides will consequently be displaced laterally towards the pit center as the lateral soil pressure will change from its at rest $\left(\mathrm{k}_{\mathrm{o}}\right)$ condition to zero, for the case of unsupported excavation.

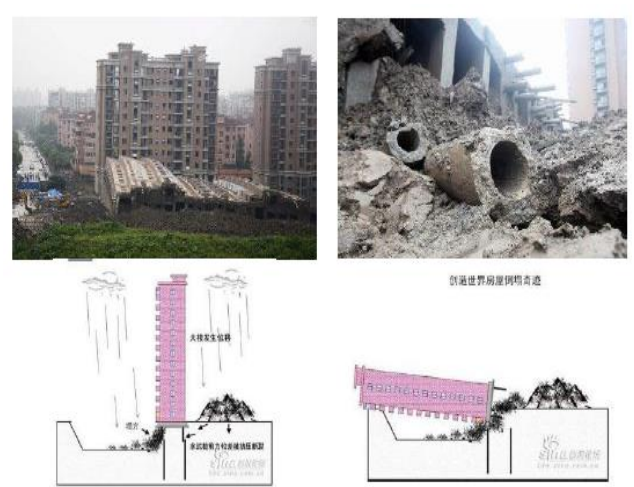

Fig. 1. Failure of a building in China in 2009 that was initiated by a nearby deep excavation and a heavy rainfall, [2 and 9].

These two patterns of soil movements are interlocked and usually occur simultaneously as the excavation process proceeds.

In this paper, the soil displacements at five observation points adjacent to an open, unsupported excavation were continuously monitored throughout 23 days period of

* Corresponding author: alaljorany@gmail.com 
excavation of about $7 \mathrm{~m}$ deep open tunnel. The finite element package PLAXIS 3D is then used to analyze the problem and compare the measured results.

\section{Field work}

The project of developing the Army Canal in the Eastern part of Baghdad city comprises of excavation of a number of open tunnels. Zayona tunnel, which is taken as the case study in this paper, is a part of this project. The tunnel occupies an approximate area of about $(45 \times 28) \mathrm{m}^{2}$. The proposed unsupported excavation depth is about $7 \mathrm{~m}$. The soil profile at the tunnel location consists of about $20 \mathrm{~m}$ deep clayey silt to silty clay layer of low plasticity $(\mathrm{CL})$. The water content is ranging from 15 to $18 \%$, the liquid limit is about 33 and plasticity index of 18. Five observation points were installed, before starting the excavation process, close to two perpendicular sides of the tunnel boundaries as shown in Fig. 2. The red line in this Fig represents the excavation boundaries. Plate 1 displays the earth works after completing the excavation. The point coordinates and elevations are measured using total station before and throughout the excavation period. Table 1 displays the initial positions of the observation points, the horizontal distance of each point from the excavation edge and the coordinates before starting the excavation process. The excavation works started in 26 June 2013 and continued for 23 days to reach a final excavation depth of $7.0 \mathrm{~m}$. Points coordinates and elevations were continuously monitored throughout the excavation period, [10 and $11]$.

\section{Results of field work}

The field observations of soil displacements are measured by means of surface trigonometry using the surveying instruments such as Theodolite and Levels. Fig. 3. displays the variation of vertical displacement with time at each of the five observation points. It can be noticed that the vertical displacement is gradually increased in the upward direction (positive) until it reached its maximum value after about 10 days when the excavation depth became $4 \mathrm{~m}$. After that, the vertical displacement tends to decrease and after about 15 days, downward movement (negative) is detected. In general, the vertical displacements of the points (1 and 3) whether it is positive or negative are greater than that of the other points because these points are closer to the excavation edge.

Fig. 4. and Fig. 5. show the variation of the lateral displacements in $\mathrm{X}$ and $\mathrm{Y}$ directions at each of the observation points. It is important to note that the tunnel local coordinates axes make an angle of about $45^{\circ}$ with the global coordinate axes. In order to figure out the lateral displacements whether they are outward or towards the excavation center, the following should be considered; for points 1 and 2, the resultant of positive $\mathrm{X}$ and positive $\mathrm{Y}$ displacements indicates outward lateral movement. For points 3, 4, and 5, the resultant of positive $\mathrm{X}$ and negative $\mathrm{Y}$ displacements indicates the outward movement. In general, the trend of variation of lateral displacement is almost similar to that of vertical displacement especially for observation point 1 .

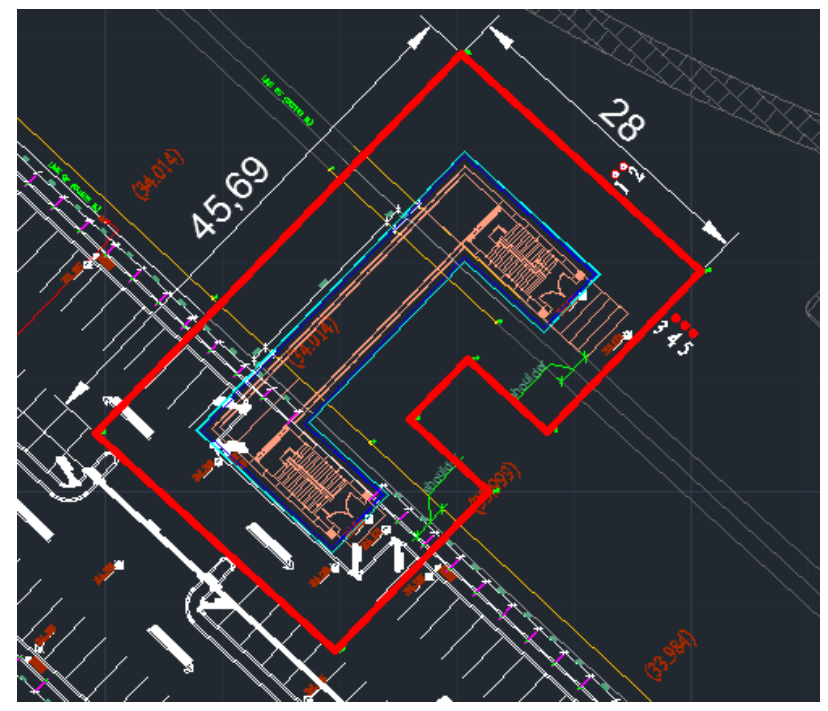

Fig. 2. The plan of Zayona Tunnel at Army Canal and Observation Point positions.

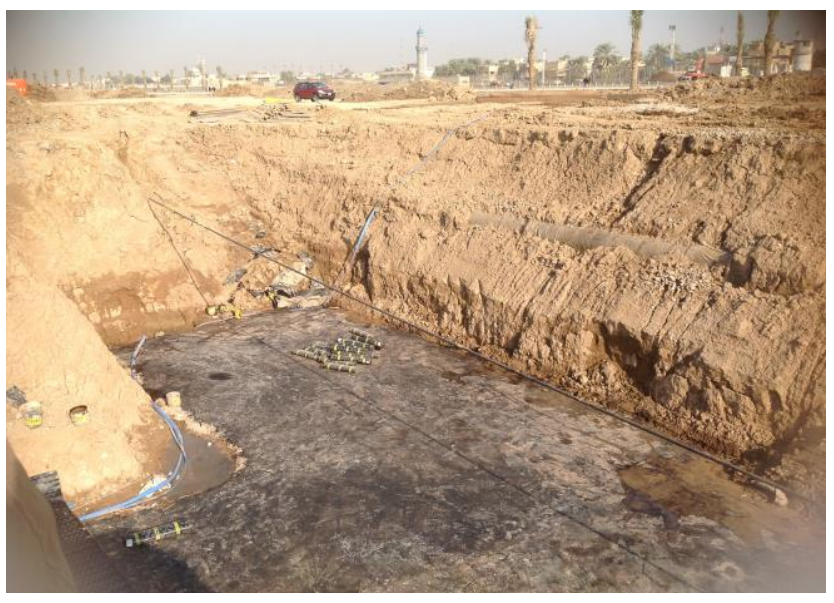

Plate 1. A Photo of the excavation work of Zayona Tunnel at Army Canal Project.

Table 1. Location and global coordinates before excavation of observation points

\begin{tabular}{|c|c|c|c|}
\hline point & $\begin{array}{c}\text { Perpendicular Distance } \\
\text { from excavation face, } \mathrm{m}\end{array}$ & $\mathrm{x}$ & $\mathrm{y}$ \\
\hline 1 & 1.25 & 450493.517 & 3688077.891 \\
\hline 2 & 2.25 & 450494.225 & 3688078.589 \\
\hline 3 & 1.25 & 450498.727 & 3688065.220 \\
\hline 4 & 2.25 & 450499.461 & 3688064.558 \\
\hline 5 & 3.25 & 450500.164 & 3688063.851 \\
\hline
\end{tabular}




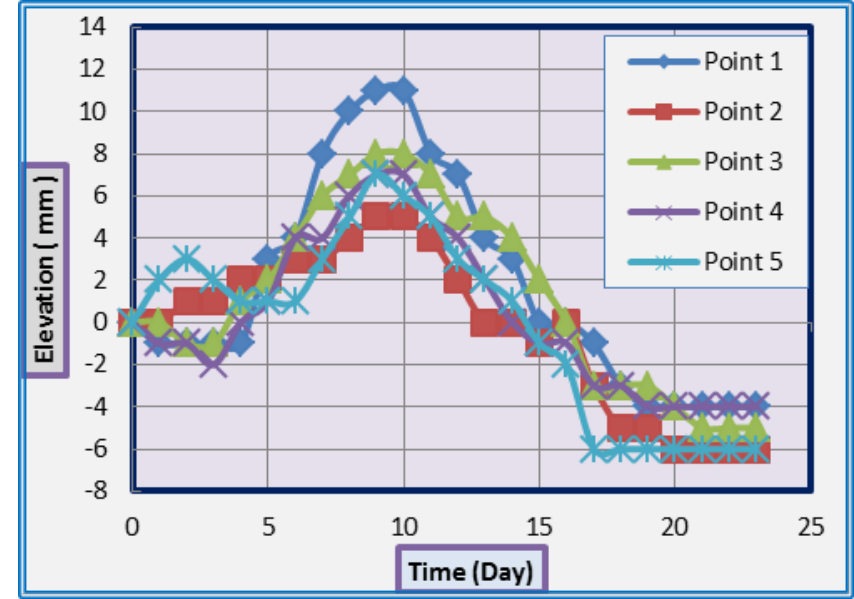

Fig. 3. Vertical displacements of the observation points

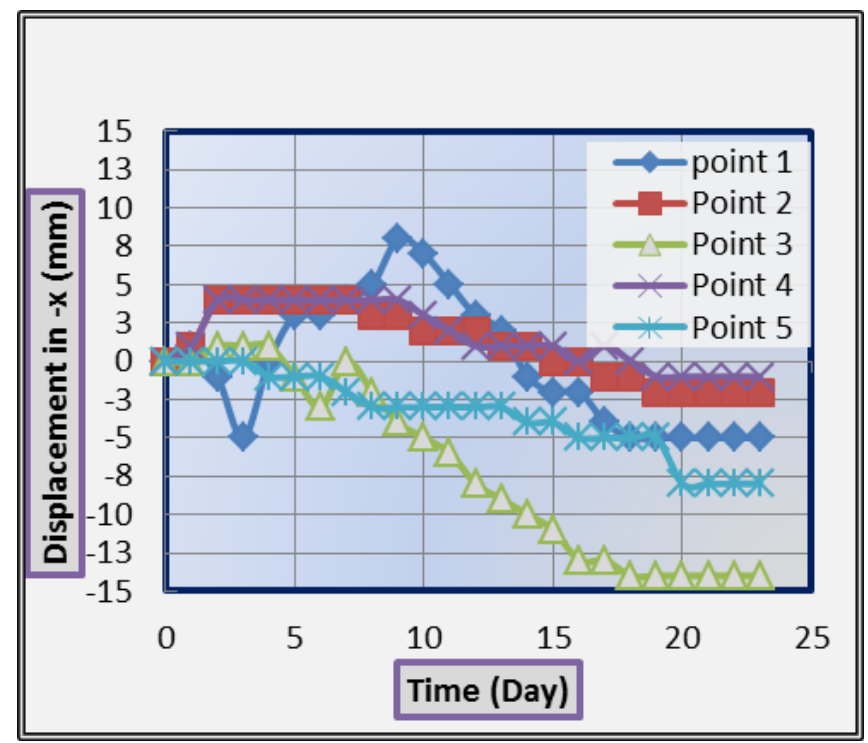

Fig. 4. X-coordinates variation of the observation points.

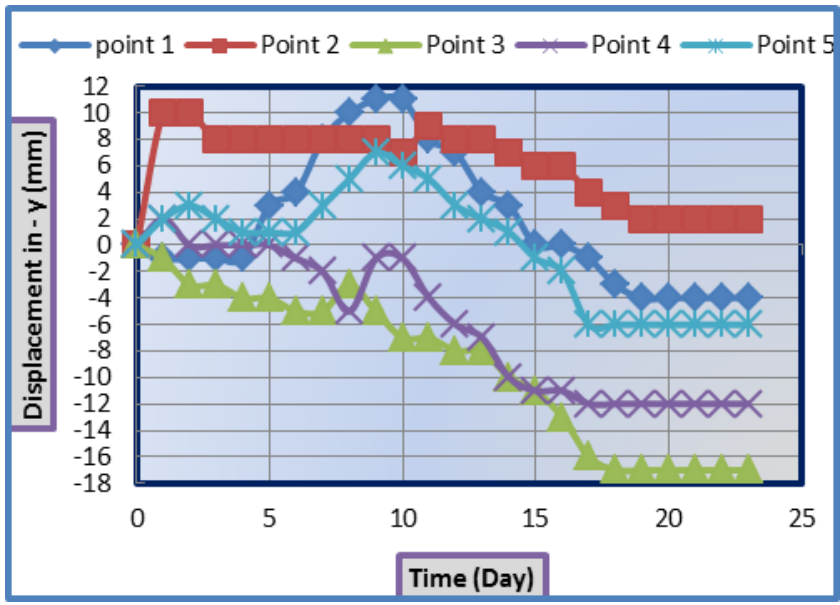

Fig. 5. Y-coordinates variation of the observation points.

\section{Finite element modelling}

A series of 3D finite element analyses are implemented, by using PLAXIS 3D Foundation program [12], to analyze the ground movement at the location of observation points. A 10 nodded tetrahedron element is used in the analyses. The Silty Clay layer is modeled as a Hardening soil model and the relevant soil properties are listed in Table 2.The excavation process is modeled as five stages. The relevant excavation depths of these stages are; 1, 2, 3, 5 and $7 \mathrm{~m}$, respectively. Fig. 6 displays the model of the tunnel excavation in PLAXIS 3D Foundation program. Fig. 7a, b and c expose the distribution of vertical ground movement for excavation depth $1 \mathrm{~m}, 5 \mathrm{~m}$ and $7 \mathrm{~m}$ respectively. In the early excavation stages, upward vertical ground surface movement (positive) is observed then changes to downward ground surface movement (negative) for all the observation points. The positive (upward) vertical movement at the central area of the tunnel bed increases with increasing the excavation depth. The positive vertical movement at the observation points increases with increasing depth of excavation down to $3.0 \mathrm{~m}$ deep and then decreases and becomes downward (negative). The upward (positive) vertical movement is in the range of 5 to $40 \mathrm{~mm}$ in central area of tunnel pit while it is range from $3 \mathrm{~mm}$ (positive) to $25 \mathrm{~mm}$ (negative) at location of observation points. Fig. 8 illustrates the distribution of lateral ground movement at each of the excavation depths. For excavation depths less than $3 \mathrm{~m}$, the lateral grounds surface movements is in the outward direction and increase with increasing excavation depth. After that depth of excavation, the lateral grounds surface movements indicate a reverse direction and the negative lateral grounds movements (towards the excavation center) are developed below the level of ground surface. The measured displacements at the observation points are compared with those obtained by the finite element analysis. Fig. 9 displays the measured and calculated vertical displacements at four of the observation points. In general, the trend of variation is almost similar. Good agreements are noticed particularly during the first 10 days when the excavation depth less than $5 \mathrm{~m}$. The comparison between measured and calculated lateral displacements at two of the observation points is displayed in the Fig 10. It can be noticed that all the measured and calculated values of lateral displacements are within the range of $+8 \mathrm{~mm}$ to $17 \mathrm{~mm}$ with almost similar trend of variation. 
Table 2. Materials properties of in situ soil

\begin{tabular}{|c|c|c|c|}
\hline Parameter & Name & Value & UNIT \\
\hline Material model & Model & $\begin{array}{c}\text { Hardening soil } \\
\text { model }\end{array}$ & - \\
\hline $\begin{array}{c}\text { Type of material } \\
\text { behavior }\end{array}$ & Type & Drained & - \\
\hline $\begin{array}{c}\text { Unit Weight of soil } \\
\text { Young's Modules }\end{array}$ & $\gamma_{\text {unsat }}$ & 18.0 & $\mathrm{kN} / \mathrm{m}^{3}$ \\
\hline & $\mathrm{E}^{\text {ref }}{ }_{50}^{\text {ref }}$ & 6500 & $\mathrm{kN} / \mathrm{m}^{2}$ \\
\hline oed & 6500 & $\mathrm{kN} / \mathrm{m}^{2}$ \\
\hline Poisson's ratio & $v$ & 15000 & $\mathrm{kN} / \mathrm{m}^{2}$ \\
\hline Cohesion & $\mathrm{E}^{\text {ref }}{ }_{\text {ur }}$ & 0.30 & - \\
\hline Friction Angle & $\phi$ & 75.0 & $\mathrm{kN} / \mathrm{m}^{2}$ \\
\hline
\end{tabular}

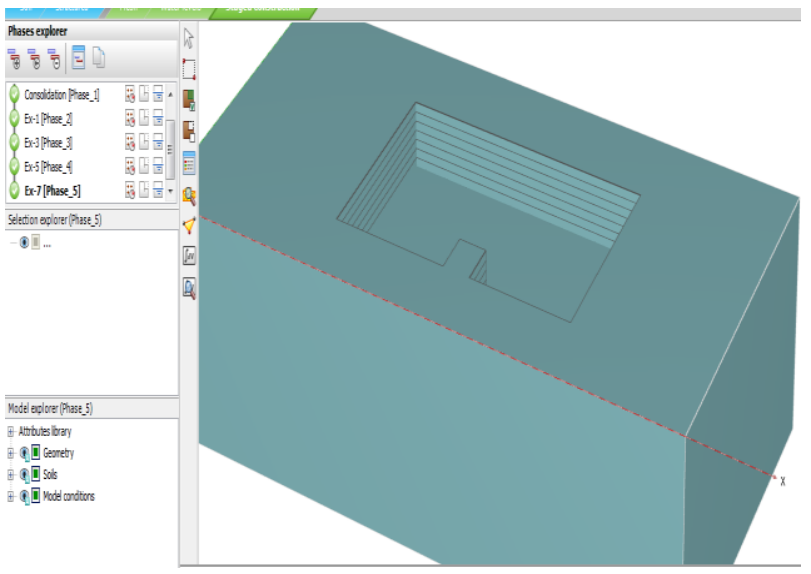

Fig. 6. Modeling of tunnel excavation in PLAXIS 3D, 2013

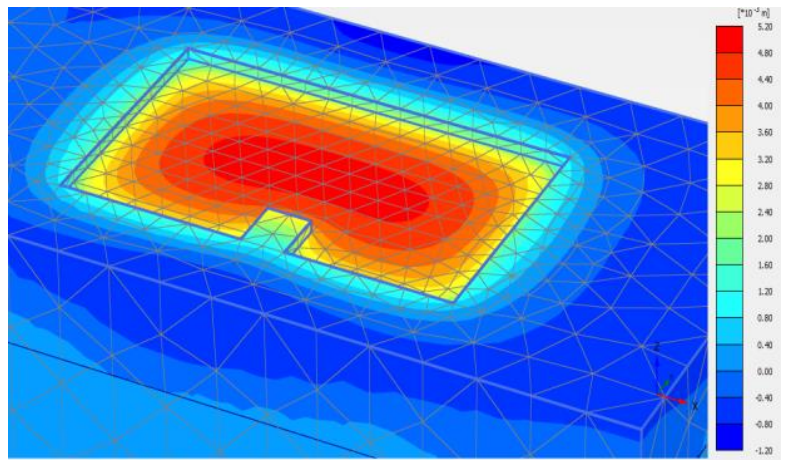

Fig. 7a Vertical ground movement distribution at excavation depth $1.0 \mathrm{~m}$

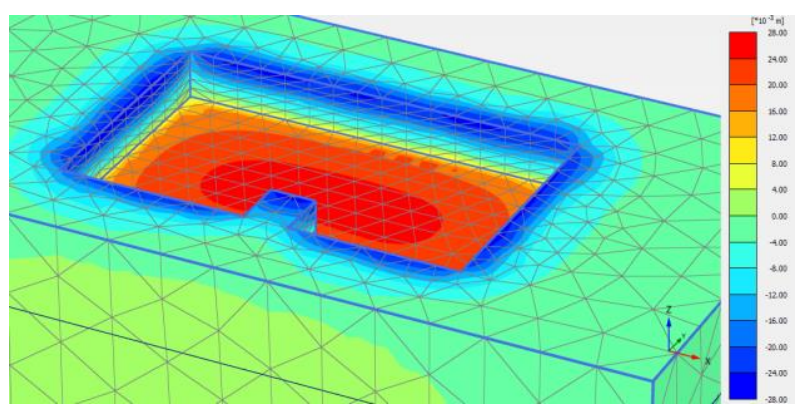

Fig. 7b Vertical ground movement distribution at excavation depth $5.0 \mathrm{~m}$

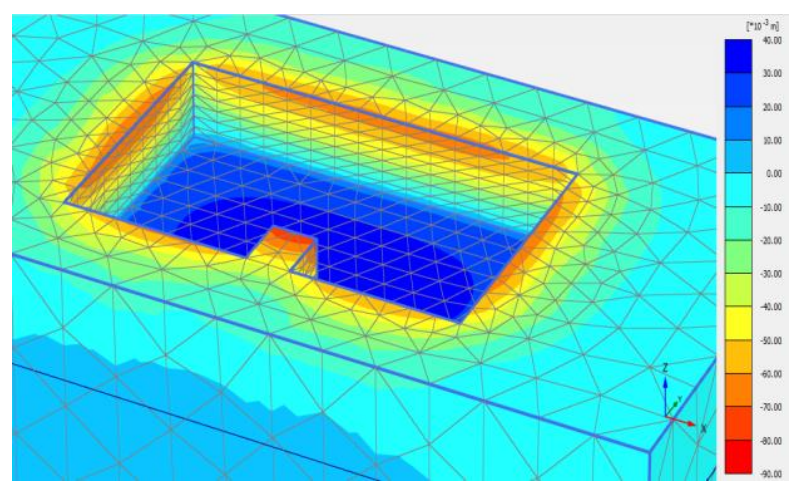

Fig. 7c Vertical ground movement distribution at excavation depth $7.0 \mathrm{~m}$

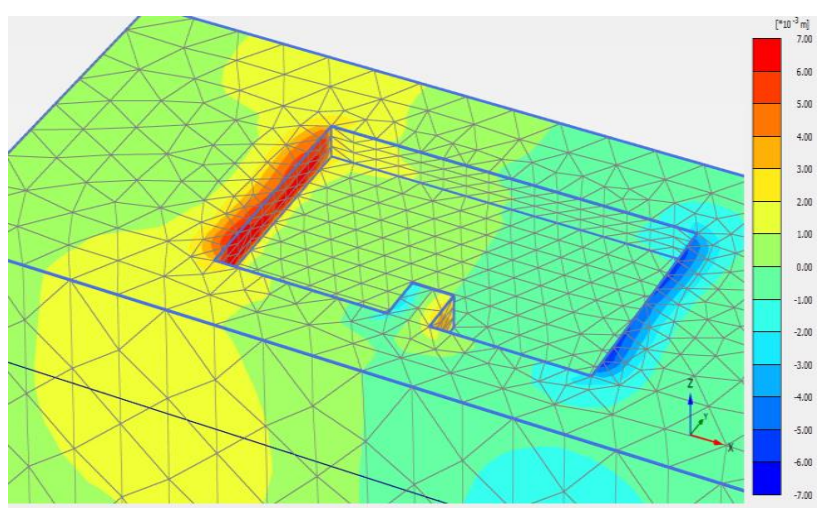

Fig. 8a Lateral ground movement distribution at excavation depth $3.0 \mathrm{~m}$

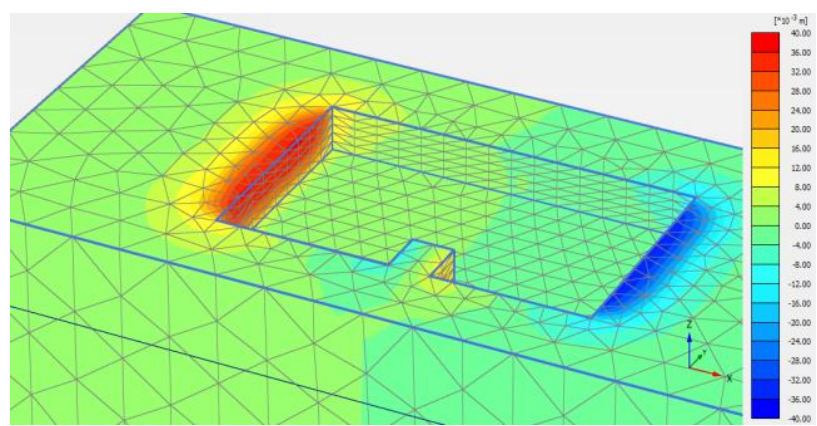

Fig. 8b Lateral ground movement distribution at excavation depth $5.0 \mathrm{~m}$ 


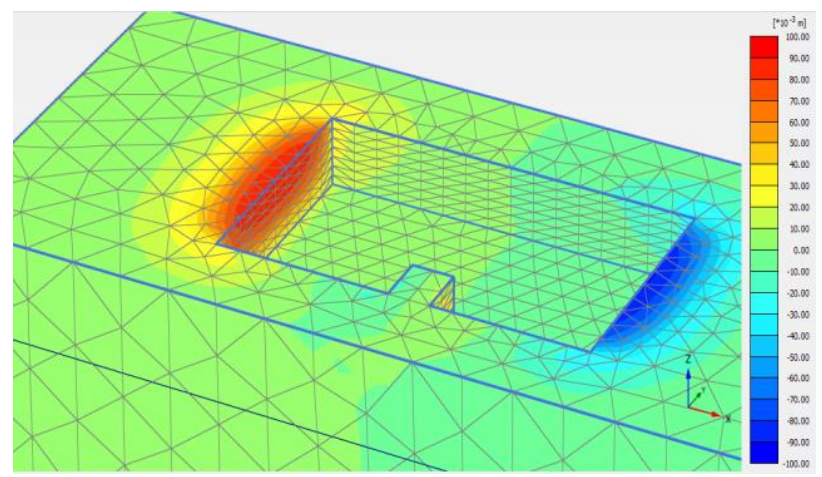

Fig. 8c Lateral ground movement distribution at excavation depth $7.0 \mathrm{~m}$

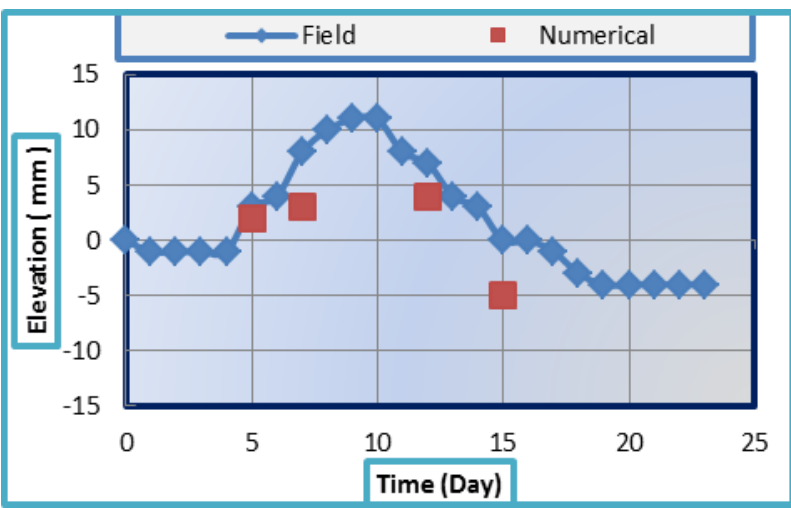

Fig. 9a. The comparisons of the field and numerical vertical ground movement at observation point no.1

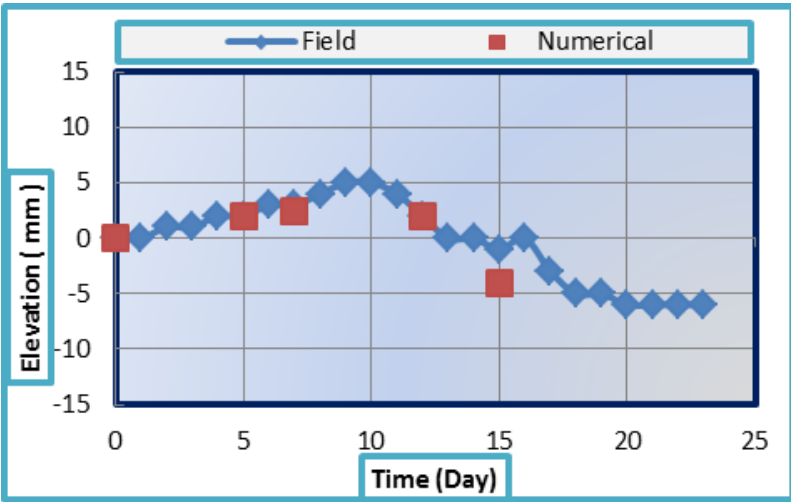

Fig. 9b. The comparisons of the field and numerical vertical ground movement at observation point No.2.

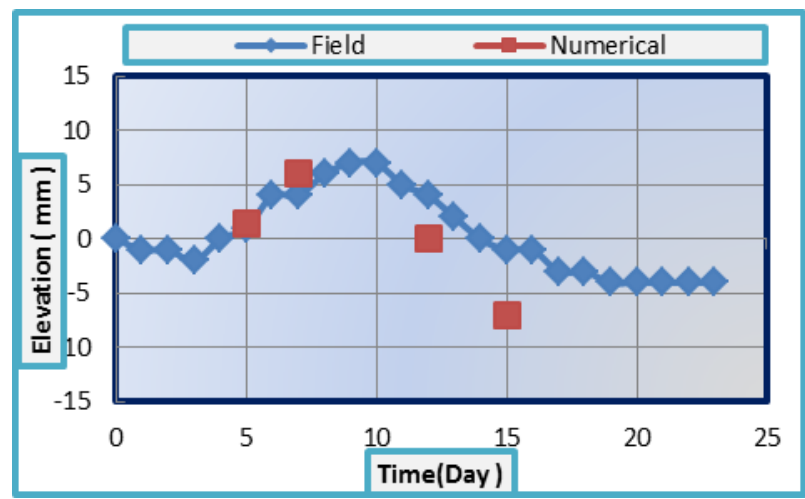

Fig. 9c. The comparisons of the field and numerical vertical ground movement at observation point No.4.

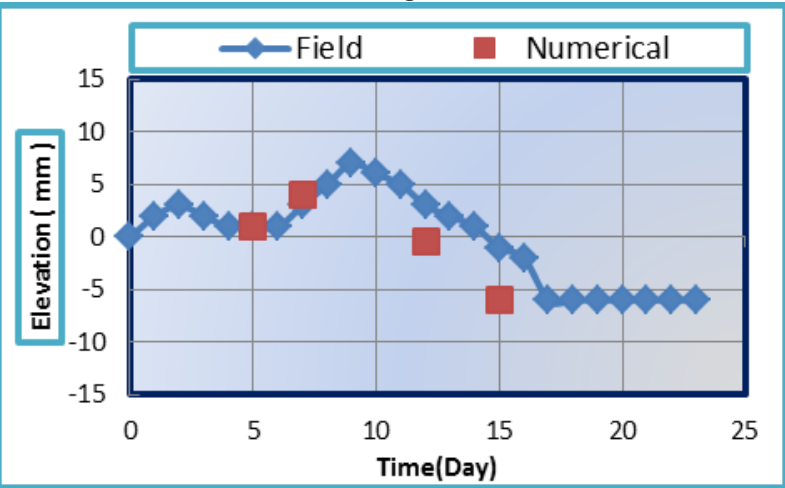

Fig. 9d. The comparisons of the field and numerical vertical ground movement at observation point No.5

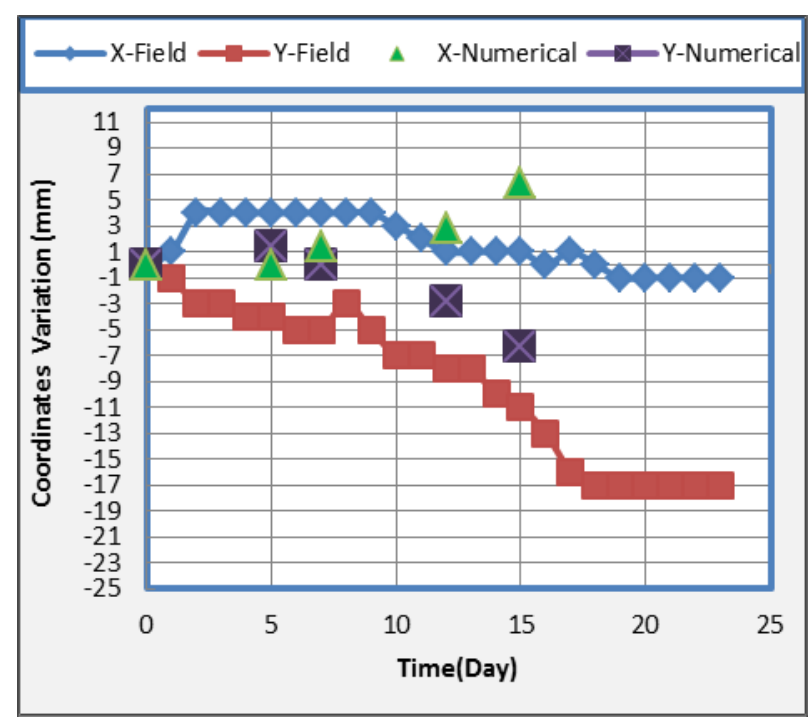

Fig. 10a. Comparison of the field and numerical lateral ground movement at observation point No.3. 


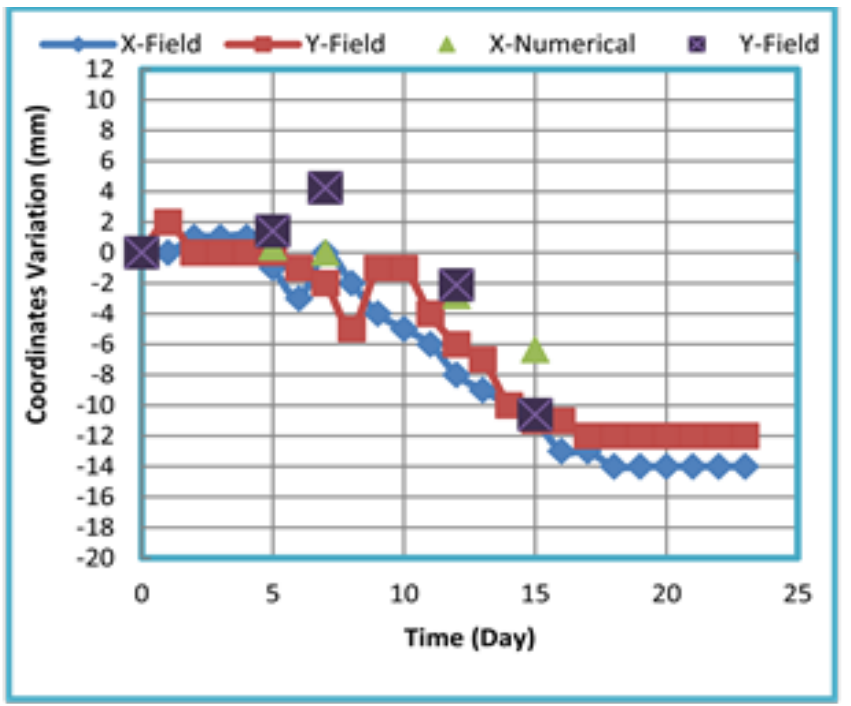

Fig. 10b. Comparison between field and numerical values of lateral ground movement.

\section{Conclusions}

All the observation points exhibit upward (positive) vertical displacement with increasing depth of excavation down to a depth of $4.0 \mathrm{~m}$ (at the tenth day of the excavation process). After that, downward vertical (negative) displacements are monitored.

In general, the values of vertical displacement at the observation points whether they are positive or negative are greater for the points that are closer to excavation boundaries.

The values of displacements obtained by the finite element analysis reveal good agreements in terms of variation trend and magnitudes with the measured ones especially for excavation depth about $5 \mathrm{~m}$ (less than the 10 days). The differences between measured and calculated values become more pronounced for excavation depths greater than $5 \mathrm{~m}$.

\section{References}

1. M. Korff, Deformations and damage to buildings adjacent to deep excavations in soft soils, (2009)

2. S. A. Ahmed, Geotechnical Engineering Group, DOI: 10.13140/RG.2.1.3966.9284, (2014).

3. X. Liu and S. Liu, Geotechnical and Geological Engineering, 30 (2), (2012).

4. J. H. Wang; Z. H. Xu and W. D. Wang, Journal of Geotechnical and Geoenvironmental Engineering, 136 (7), (2010).

5. C.Y. Ou, J.T. Liao, and W. L. Cheng, Géotechnique, 50 (3), (2000).

6. W. Allen Marr and M. Hawkes, Displacement-Based Design for Deep Excavations, Earth Retention Conference (ER), (2010).
7. M. Korff, and R.J. Mair, Proceedings of the 18th International Conference on Soil Mechanics and Geotechnical Engineering, (2013)

8. M. Korff, and R.J. Mair and, F. A. F. Van Tol, Journal of Geotechnicaland Geoenvironmental Engineering, 142 (8), (2016)

9. Chai, J.; Shen, S.; Ding, W.; Zhu, H. \& Carter, J. China, Computers and Geotechnics, 55, (2014).

10. A. N. Aljorany and Gh. S. Al-Qaisee, Journal of Engineering, 22 (5), (2016).

11. Gh. S. Al-Qaisee, Effects of Unsupported Excavation on a Nearby Pile-Soil System, PhD Thesis, Department of Civil Engineering, University of Baghdad, Iraq, (2015).

12. Plaxis 3D foundation; Material models manual V1.6 (2013). 